\title{
As quatro estações
}

\author{
MAgAli LeITE de FreitAs*
}

\section{Enredando-se e enredando-nos,}

\section{prazerosamente}

Este texto trata de uma experiência de formação de educadores desenvolvida ao longo de 12 meses, no âmbito do projeto Gestores de Aprendizagem Socioeducativa - Projeto coordenado pelo CENPEC e de iniciativa da Fundação Itaú Social e Unicef, que aconteceu no período de março de 2005 a março de 2006, na Baixada Santista, Estado de São Paulo.

A autora e participante do Projeto, Magali Leite de Freitas, presenteia-nos com a riqueza de seu olhar e de sua narrativa. Assina um texto que também ilumina a presença de outros autores que a acompanharam nesta experiência. Discorre, com leveza, as aprendizagens que obteve nos seus encontros com pessoas, textos, espaços, idéias, experiências e práticas educativas propostos no projeto.

Nesses encontros, Magali enredou-se numa teia, descobrindo novos modos de se relacionar com outros profissionais, de organizar seu trabalho, de aprender, de ousar novos caminhos e também valorizar o seu próprio trajeto e de seus pares - todos educadores comprometidos com uma ação de qualidade para crianças e adolescentes que freqüentam as organizações não-governamentais.

A escrita livre oferece também ao leitor a oportunidade de fazer perguntas acerca do que queremos, de fato, com as experiências educativas:

- desejamos criar e fortalecer relações de interdependências, no sentido de produção social de novos patamares de civilidade, tal como nos sugere Norbert Elias?

- essas relações nos levariam a recolocar a dimensão da autonomia nos processos e práticas educativas?

Stela FERREIRA PESQUISADORA DO CENPEC
Outono, inverno, primavera...

\section{Outono foi a estação anunciada para essa história} começar. Nosso primeiro momento foi a apresentação do roteiro de viagem a bordo do Gestores de Aprendizagem Socioeducativa. Nós estávamos naquele espaço pequeno, na saída do elevador, aguardando uma outra reunião terminar para começarmos. Era uma reunião sobre o circuito dos Fortes da nossa região.

Isto me faz lembrar de histórias, fortalezas, piratas e capitães... Lembram-me aventuras que desbravam terras e mares e de histórias que se escrevem. Sinais e pistas de cartografia já se faziam presentes no começo desta história. Cartografia, instrumento metodológico, que nos leva a ver tantas possibilidades no trabaIho com as pessoas! Pessoas brancas, negras, amarelas, vermelhas, de todas as cores, formas e jeitos de lindamente ser, que se encontram, desencontram-se para tornar a se encontrar.

0 nosso primeiro encontro se deu mesmo naquele espaço meio desajeitado, quase um aquário da Secretaria. Detesto aquela sala de repartição pública que as pessoas, às vezes, utilizam para ações que não devem ser públicas. Bom, mas quando cheguei, estavam as três, como sempre, organizando o espaço e os materiais... quanto cuidado, quantas novidades e surpresas deliciosas!

No começo, rostos desconhecidos, bom-dia tímido, distante, pouco afetuoso. Com o passar das estações, quanta afetividade! Timidez? Que nada! 0 grupo que 0 diga, na dinâmica, após o almoço, da última estação. Desconhecidos? Hoje, todos muito familiares. Ah! E os nossos "bons-dias" foram tantos, de todas as formas, as mais cuidadosas possíveis!

\footnotetext{
* Magali Leite de Freitas é Psicóloga e Técnica da Secretaria Municipal
} de Assistência Social de Santos, SP. 
E as nossas expectativas? No começo do outono, a Aquarela lançou no grupo "que com cinco ou seis retas é fácil fazer um castelo [...] e se faço chover com dois riscos tenho um guarda-chuva. Se um pinguinho de tinta cai num pedacinho azul de papel, num instante imagino uma linda gaivota a voar no céu". Ah! E como imaginamos! Imaginamos juntos a criança do nosso dia-adia, o navio fantasma, gênios dentro de lâmpadas e rotas de navegação.

No inverno, sonhamos projetos, traçamos a cartografia, conhecemos as linhas de rota, dialogamos com as distâncias entre o sonho e o real, experimentando relacionamentos, interesses e sentimentos. Enfim, descobrimos que "o seu olhar melhora o meu". Ah! E este é um caminho sem volta! Talvez, seja a descoberta da rosa dos ventos.

No final da primavera, a nossa expectativa estava estampada na foto da rede de mãos, legendada pelo Rosa "porque a vida é um caldeirão de todos. Por todos remexida e temperada”. Foi também nesse final de primavera, que a Aquarela voltou nas mãos de alguém anunciando "um navio de partida com alguns bons amigos, bebendo de bem com a vida".

Durante o nosso percurso, cultivamos sonhos, mas também desenhamos as imagens que a nossa imaginação permitiu. Sem pensar em Gaudi, construímos torres. Foi um desastre! Porém, inspirados em Rodin, construímos esculturas, exploramos movimentos, expressões e olhares. Às vezes, como escultores, outras, como bailarinos dançando ao som das mais variadas trilhas sonoras, resgatando, nas ruas da infância, as pedrinhas de brilhantes colocadas quando fui ao Itororó beber água.

\section{Saberes e sabores, povoados e pessoas}

\section{Ah! Como compartilhamos... leituras de cartografias,} de textos e de histórias. Lembram do nosso herói de gemas preciosas? Compartilhamos poesias, memórias e diários escritos de tantos jeitos, lindamente, diferentes. Impressões únicas! Nossa história sendo registrada, também, de muitas formas. Com as mãos de todos - não somente com as da Chantal, que registrava tudo sem parar, mas todas as mãos - registrando aqui e ali, de uma forma ou de outra, com câmeras fotográficas, tintas, lápis, canetas e olhos!

Os nossos olhos... quantos registros! Será que aprendemos a olhar como cartógrafo? Como educador-cartógra- fo, que vai registrando, cuidadosamente, personagens, objetos e lugares... próximos e distantes, imagináveis e inimagináveis, prováveis e improváveis.

Isso foi um convite a ousar, a re-significar nossa prática, a se inspirar com Manoel, Carlos, Saramago, Mário, Paulo, Kazuo, Rosa e tantos outros. Será que aprendemos a rota da presença, da diversidade, das potencialidades e da riqueza presente nas relações? Esse lugar onde as coisas acontecem!

Assim aconteceu conosco também!

Nós fomos ficando, a cada estação, cada vez mais à vontade, mais próximos uns dos outros, mais conhecedores. Conhecedores? Não, não... não é mais nem menos conhecedor. Talvez, "tateadores" uns dos outros, contato e com o tato. Aliás, os nossos sentidos foram aguçados e, com eles, fomos dando sentido aos nossos encontros. 
Momentos deliciosos dos cafés, dos apetitosos almoços e lanches do final da tarde. Olhos sempre arregalados para as podres delícias sobre a mesa. Momentos de chegar, de se aproximar, de compartilhar sabores e saberes. Sabor de sonho de valsa, sentido lindo do sonho, da valsa, do doar-se, do alimentar o outro, do alimentar-se e do alimento fraterno. Belo momento oferecido ao grupo pelas nossas três encantadoras de sonhos. Sonhos... sabor que nos move, movimenta nossos saberes.

Os saberes do grupo foram contando a nossa história. História que se fez nos encontros do grupo com a certeza, a dúvida, o humor, a seriedade, a ansiedade, a tranqüilidade, a tagarelice, o silêncio, o medo, a coragem, o choro, a tristeza e a alegria de cada um. Porque todos esses sentimentos habitam cada um de nós em momentos diferentes. E, num movimento de diferenciação, fomos nos vendo com as coisas de um, com as de outro, guardando dentro da gente um pouquinho de cada pessoa. Ficamos assim... povoados de pessoas. Somos povoados por grupos que fazem ou fizeram parte da nossa vida.

\section{Tempo, tempos, memória, memórias}

As estações foram passando e, a cada reencontro, um misto de sensações, de coisa perdida que se encontra adicionada a uma pitada de estranheza. Ora oscilando entre o doce e o amargo, entre o encontro e o desencontro, entre o conhecido e o desconhecido.

Coisa que vai se acomodando devagar, que vai fazendo parte de mansinho, que vai compondo com tantas formas diferentes de se manifestar.

Diferentes territórios existenciais, encharcando de sentido esse percurso, que vai se construindo como memória.

Memória que dispara sentimentos. Memória que pode ser individual ou coletiva, pode ser do grupo ou da humanidade. História da humanidade, construída no tempo. Idéia de tempo... Às vezes, não é o meu tempo, é o deles! Em outras, pode ser o nosso. Possibilidades de tempo: tempo de esperar, de chegar, de partir, de plantar, de colher, de chorar, de sorrir e de se encantar...

Há, também, o tempo da delicadeza! Delicadeza de ouvir, de falar, de olhar e de acolher. A delicadeza de abarcar o tempo de todos num só tempo.

Grande habilidade das nossas encantadoras de sonhos... Forma delicada de entrelaçar o diverso, o pessoal e o profissional, de potencializar, de assanhar os desejos, os sonhos nossos de cada dia. Forma de um saber regado de simplicidade, espontaneidade e proximidade. De um saber que não é prepotente, autoritário e soberbo, e, sim, delicadamente generoso.

Tomara um dia sejamos todos assim! As crianças, os adolescentes e as famílias agradecerão!

Eu estarei sempre povoada por vocês, todos, que com seus jeitos diferentes de ser e estar no grupo, ensinaram-me tantas coisas sobre eu mesma, que me deram este sentimento bom de pertencimento, que me deram coragem de compartilhar, nunca antes compartilhada, a minha forma de registrar as coisas que tocam devagar e deliciosamente o meu ser.

Amei a nossa temporada juntos.

Até o verão!

Magali 


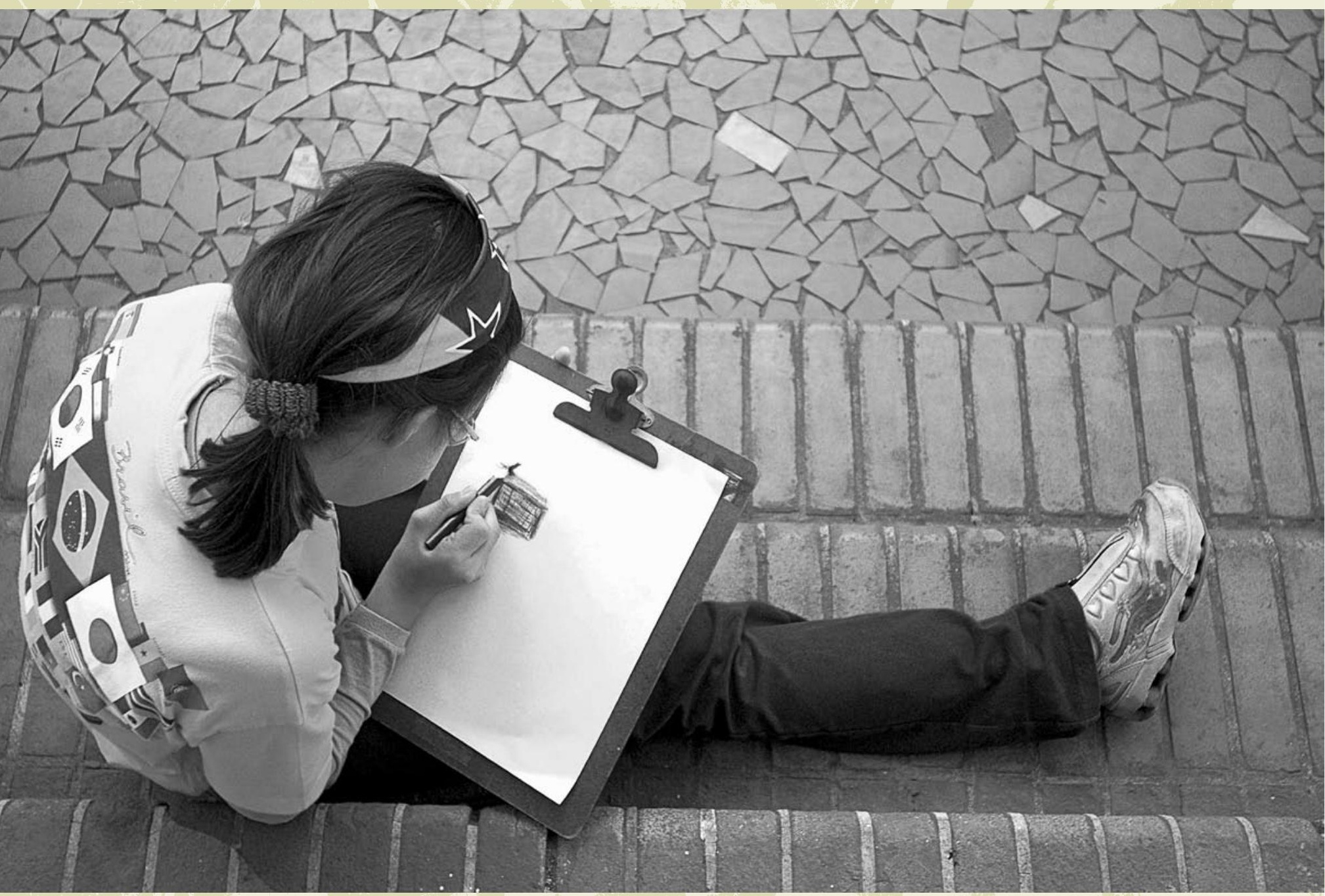

